\title{
EL SURREALISMO ARGENTINO Y SU PRAXIS
}

\author{
Kira Poblete Araya
}

La primera manifestación del surrealismo en Argentina fue la revista $Q U E$, publicada en 1928, fruto de las actividades de un grupo de jóvenes que se había formado dos años antes, a instancias de Aldo Pellegrini, quien fue su difusor y.propulsor durante más de cuarenta años. Podría decirse que él fue el nexo, el eslabón que unió todas las actividades que se llevaron a cabo bajo la advocación de ese "ismo" artístico.

Como testimonio de esas experiencias han quedado las revistas literarias que aunque de vida breve, aglutinaron a los poetas que se sentían atraídos por ese nuevo credo literario y difundieron sus poemas y la doctrina que sustentaban.

La serie se inició con $Q U E$, en 1928, y continuó después de un largo silencio con CICLO, A PARTIR DE CERO, LETRA $Y$ LINEA, BOA y finalizó con LA RUEDA, en 1967. Ellas son el cañamazo sobre el cual se puede-trazar su trayectoria y observar los distintos momentos de su desarrollo. Si bien el grupo que lo sostuvo no tuvo una fuerte cohesión, lo llevó a la práctica sin compromiso político, acentuando su matiz estético e introspectivo y evolucionó separado de la pintura y de otras manifestaciones literarias. 
En esa trayectoria se distinguen tres fases: 1. Iniciación y búsqueda (1928-1949); II. Cristalización y auge (1950-1957); y III. Evolución y transformación (1958-1973).

1. Iniciación y bưsqueda (1928-1949).

El grupo inicial formado por Pellegrini en 1926 contó entre sus adherentes a Elías e Ismael Piterbarg, Marino Cassano y David Sussmann. El mismo Pellegrini ha dejado constancia de ese momento en cartas que enviara a Stefan Baciu y Graciela de Solal. También en ellas indica los primeros documentos surrealistas que llegaron a sus manos: el Primer Manifiesto Surrealista y el primer número de la revista $L A$ REVOLUTION SURREALISTE, que fueron el punto de partida de esas primeras experiencias, cuyo resultado recogió $Q U E$, que editó dos números.

El primero apareció en noviembre de 1928, estaba dirigido por Elías Piterbarg y publicaba en sus páginas los poemas y manifiestos del grupo sin mencionar ni difundir los que le habían dado origen. Lo primero que llama la atención, es su sumario escueto; consta de una primera sección llamada simplemente "Justificación" y luego las restantes, están numeradas del 1 al 6. Cada una está a cargo de un redactor identificado por un seudónimo. Como eran sólo cinco, uno escribe dos secciones. Ese es el caso de Elías Piterbarg, que escribe en las 1 y 2, bajo los nombres de Esteban Dalid y Felipe Debernardi; luego, la 3 es escrita por Pellegrini como Adolfo Este; la 4, por Marino Cassano como Julio Lauretta; la 5, por Ismael Piterbarg como Raúl Pembo; y la 6, por David Sussmann, bajo el nombre de Julio Trizzi.

El editorial "Pequeño esfuerzo de justificación colectiva", aparece sin firma, y como el título lo indica, su propósito es justificar la publicación de la revista y su orientación

1 Stefan BACrU. Surrealismo latinoamericano: preguntas y respuestas Valparaiso: Ediciones universitarias de Valparaiso, 1978), p. 17.

Graciela de soLA. Proyecciones del surrealismo en la Argentina (Buenos Aires: Ediciones Culturales Argentinas, 1967$)$, p. 111 . 
literaria. Sus declaraciones se hacen más explícitas en las secciones 1 y 2 , en las cuales Piterbarg manifiesta en un tono agresivo, desafiante y condenatorio, su disconformismo con la sociedad en que vive y su estilo de vida. El breve ensayo teatral que sigue a continuación, "Motivo: tres escenas en un acto", es la representación irónica y sarcástica de esa vida que critica.

De los poemas que se incluyen, se destacan "Fragmentos de poemas filosóficos" de Pellegrini, breves párrafos en prosa, en los que la idea filosófica, fruto de la reflexión, aparece en simbiosis con la imagen irracional. Cada uno de ellos es el intento del poèta de integrar la conciencia $y$ el inconsciente en una unidad indisoluble.

Los poemas restantes responden a las inquietudes manifestadas en su nota editorial pero no han alcanzado aún, una auténtica expresión poética.

El segundo número de QUE se publicó en diciembre de 1930, hubo algunos cambios en su diagramación y su dirección estuvo en manos de Pellegrini. Presenta varios ensayos de justificación. En el primero, "Por esta puerta abierta, los señores pueden entrar en el recinto de los fantasmas", firmado por A. E. (A. Pellegrini), se expresaban los anhelos que ponian de manifiesto los objetivos del grupo:

QUE no es simplemente un grupo de gente que tiene como misión publicar una revișta (lo demuestra el intervalo de más de dos años que separa sus dos números), sino que intenta CONTENER, EXPLICAR Y SI ES POSIBLE RESOLVER, UN ESTADO DE ESPIRITU EXCEPCIONALMENTE ABUNDANTE EN ESTA EPOCA... (p. 1) $)^{2}$.

Además de buscar la modificación del espíritu del individuo, promovían un cambio de vida, el cambio de la sociedad, cuyos valores $e$ instituciones cuestionaban, posición que aparece explícita en "Libertad de los solenoglifos y otras

2 Los números de las páginas de las citas referidas a las revistas surrealistas consideradas, figurarán al pie del texto citado. 
cosas dichas entre dientes", texto que también pertenece a Pellegrini.

A continuación, encontramos poemas, composiciones breves, producto de la escritura automática, cuyo procedimiento nos lo revela David Sussmann en uno de los fragmentos de su texto "Vomitando en seco":

Se reunían alrededor de una mesa. Eran cinco.

Cuatro debían llenar en cinco minutos una página en blanco, mientras el quinto reloj en mano, dejaba caer de su boca estúpidas palabras incoherentes. Estas se entrelazaban caprichosamente sobre los papeles

produciendo los más bellos poemas. (p. 15).

Como ejemplo de esa técnica, citamos el siguiente poema de Pellegrini:

\section{MAÑANA}

Redes de sueños que recogen peces atónitos

Despiértate

El día sin cielo atraviesa lentamente tus ojos

Mis palabras buscan inútilmente

el furor de la noche ha arrancado tus orejas (p. 7).

La segunda revista de este periodo fue CICLO, cuvos directores eran Aldo Pellegrini, Enrique Pichon Rivière y Elías Piterbarg, y como colaborador, David Sussmann. Su orientación comprendía la información, la crítica, el ensayo no sólo sobre literatura, sino también, sobre pintura, escultura y arquitectura. La mayoría eran colaboraciones de prestigiosas figuras del ambiente artístico internacional y se conciliaba el espíritu surrealista con el arte concreto. Alcanzó a publicar dos números, el primero correspondió a ñoviembre-diciembre de 1948 y el segundo a marzo-abril de 1949.

En el primero se incluyó un artículo de Piterbarg, "Surrealismo y surrealistas en 1948", (él había visitado París ese año y se había relacionado con el grupo francés). Es una interesante crónica en la cual hace el análisis de la 
situación del surrealismo y saca sus conclusiones. Primero nos da una imagen de las reuniones que se llevaban a cabo ese año en París, relata su entrevista con Breton, Ristich y Tzara y finalmente resume sus opiniones y critica 10 que ha visto y oído. Esta nota permite comprender su posterior alejamiento del movimiento.

En el segundo número se continuó con la línea informativa y crítica iniciada en el anterior. Referente al surrealismo, publica una conferencia de Pichon Rivière sobre la vida e imagen del $C$. de Lautréamont y un ensayo de Pellegrini, "La conquista de lo maravilloso", en el cual expone su pensamiento estético y filosófico sobre la experiencia poética y a la luz de los postulados del surrealismo. Esta publicación cierra la primera fase de existencia del grupo.

II. Cristalización y auge (1950-1957).

Esta fase se inicia con las conferencias sobre el surrealismo que ofreció Pellegrini en el Colegio Libre de Estudios Superiores de Buenos Aires en julio de 19503. La primera, "El movimiento surrealista", se inicia con la revisión del estado del movimiento en ese año (1950), y a continuación traza el panorama cultural y social de Europa que le dio origen. La segunda, "Nacimiento y evolución del movimiento surrealista", se refiere a su desarrollo y a sus manifestaciones.

Dos años más tarde, apareció A PARTIR DE CERO, "Revista de poesía y antipoesía", dirigida por Enrique Molina y reunió a su alrededor a Aldo Pellegrini, Carlos Latorre y Julio Llinás. Pellegrini era el único que había pertenecido al grupo inicial. Alcanzó a publicar tres números.

El primero se publicó en noviembre de 1952, constaba de ocho páginas y fue una novedad por su formato oblongo (48 cm. X $16 \mathrm{~cm}$.), sus ilustraciones y la impresión vertical de sus hojas centrales. Además de los poetas citados, colabora-

3 Las conferencias mencionadas fueron publicadas en la revista de la Institución, CURSOS $Y$ CONFERENCIAS $\mathrm{N}^{\circ} 222$ (septiembre, 1950 ). pp. $\frac{298-314: \mathrm{N}^{\circ} 226-}{227-228}$ $\frac{227-228}{664}$ (enero, febrero, marzo, 1951), pp. $641-$ 
ron César Moro, Benjamín Pérę y Gisélle Prassinos y con algunos dibujos, J. Batlle Planas.

A manera de editorial y programa de acción del grupo, aparece el ensayo "Vía libre", de Molina, en el cual expone sus ideas sobre la poesía. Comienza por proponer la identificación de poesía y vida como conducta fundamental, siguiendo la senda iniciada por Rimbaud y Lautréamont, hasta llegar a Breton y el surrealismo.

Otro ensayo que figura, es "El poder de la palabra", de Pellegrini, que en cierta forma desarrolla filosóficamente las ideas que Molina enuncia poéticamente. Este análisis de la función de la palabra, desde diferentes ángulos y puntos de vista, a fin de determinar el valor filosófico, semántico. comunicativo y poético, constituye otro documento útil para comprender la posición teórica del grupo.

A continuación figuran un poema de cada uno de los integrantes del grupo. El primero de C. Latorre, "Código secreto", sugiere a la amada a través de imágenes nacidas de la fusión de la comunicación, la memoria, la infancia y el amor. Le sigue "Ella aguarda alguna cosa", de J. Llinás, donde también la mujer es el vínculo que une y sostiene la estructura del poema. Es una mujer que participa de la naturaleza y del ser humano, de la vida y de la muerte, es pasiva y activa. El tercero, "Donde quiera que estés", pertenece a Molina, quien crea un universo a través de imágenes como éstas:

.. la casa emerge de nuevo a flor de tierra

Enroscándome su larga cabellera a la garganta con una dulzura cada vez más feroz

A riesgo de estrangularme (p. 5 ).

Ellas se desgranan como un torrente y nos transportan a un mundo visto apasionadamente, en el cual la naturaleza recobra su capacidad de asombro y el hombre está solo a la intemperie a la espera de una compañía. Es una construcción de palabras, ritmo e imaginación de un mundo en el cual los objetos nacen de las palabras y los anima la fuerza de la imaginación, el sueño, la memoria, el subconsciente, etc., 
y crean la realidad.

El último, "Los días imposibles", de Pellegrini, es el más extenso de todos, sus imágenes surgen de la fusión de sus cavilaciones filosóficas, sus preocupaciones sociales $\mathrm{y}$ el subconsciente que aflora bañándolo todo y estableciendo comunicación entre la vigilia y el sueño.

El seğundo número se publicó en diciembre del mismo año (1952), conservando el formato del primero y presentaba colaboraciones de A. Breton, Paul Eluard y George Schehade. Como en el anterior aparecen dos ensayos teóricos, uno de Molina, "Un golpe de dedo sobre el tambor", en el cual pone énfasis en la crítica del ambiente literario argentino $y$ el concepto de poesía que en él domina. Y el otro, "El huevo filosófico" de Pellegrini, considera la concepción surrealista del conocimiento $v$ su fundamentación como método de aquél, que no es otro que la poesía.

En relación con la expresión poética, aparece un homenaje a Paul Eluard, a través de una selección de poemas traducidos por Molina y Pellegrini y dos poemas que son colaboracines de Antonio Porchia y Juan Antonio Vasco.

Porchia fue uno de los poetas latinoamericanos que Breton incluyó en la lista de poetas surrealistas. En ese poema, "Voces", domina el hermetismo, el tono proverbial y sus versos responden a la estructura del apotegma, en los que trata de resolver las contradicciones que la realidad v lo subjetivo nos presentan, ejemplo de ellos son los siguientes:

Lo antes que yo y lo después que vo casi se han unido, casi son uno solo, casi se han quedado sin yo (p. 6).

El poema de Vasco, "El arpa abandonada", presenta una serie de imágenes que se unen por el ritmo, la presencia del objeto que da nombre al poema y el sujeto que lo escribe, en una relación múltiple, que crea nuevos objetos o imágenes de una nueva realidad.

En este número aparece la-primera muestra de narrativa surrealista, "El expósito", de Latorre. Su tema central 
es la historia de un niño abandonado que tiene como telón de fondo una función de cine, el público, la realidad, la irrealidad, la vida y la muerte, que se entrecruzan como los hilos de una madeja, que no sería otra cosa que la metáfora de la situación del hombre indefenso frente al mundo.

El tercer y último número de esta revista se publicó en septiembre de 1956, después de casi cuatro años de silencio. Se presenta como segunda época y a cargo de un comité de redacción integrado por C. Latorre, J. Llinás, F. J. Madariaga, Enrique Molina y J. A. Vasco. Como colaboradores figuran Antonín Artaud, Leonora Carrington, Ingemar Gustafson, Blanca Varela y Olga Orozco.

Su formato también tienen variaciones, es más pequeño, sigue téniendo forma rectangular $(35 \mathrm{~cm} . \times 13 \mathrm{~cm}$.$) , dieciséis$ páginas, de las cuales las centrales tienen una aleta extensible, son más cortas que las otras y están dispuestas en forma escalonada. Los textos poéticos se complementan con ilustraciones de J. F. Fassio, E. Molina, Alvaro Rodríguez, J. Llinás, Martha Peluffo y C. Latorre. En cierta forma reúne la expresión surrealista en sus dos versiones: literaria y plástica. Su impresión está hecha en cartulina.

La nota editorial, "Cambio de domicilio" (segunda época), de Molina, ratifica el propósito de los números anteriores: iniciar la labor "a partir de cero"; cambiar la vida; unificar poesía y vida y continuar con la crítica de la literatura argentina. A continuación el ensayo de Pellegrini, "Comentario a tres frases de autores célebres (La celebridad es la conciencia de horror)", pone en práctica la crítica propiciada por Molina.

En lo que se refiere a creación poética, se publican dos poemas manuscritos (escritura automática), de C. Latorre. En ellos dominan las oposiciones $y$ las asociaciones por afinidad, como en los versos siguientes:

Espacio. El suyo y el mío y el necesario para el bosque. El agua del mar no cae al vacío, al espacio. Está arribe y abajo, y no cae ... (p. 6)

Otro poema que se destaca es "La jaula del sol", de F. Madariaga. Llaman la atención sus imágenes en las que 
el sol, la naturaleza y el poeta se unen creando una realidad diferente, que fusiona lo maravilloso y la belleza, generando así su sentido poético.

$Y$ el último poema que se incluye es de J. A. Vasco, "Hay abundancia de todo", figura en forma manuscrita y tiene cierta extensión. Su estructura se sustenta en una serie de paráfrasis que tienen como palabra pivote "hay" que se abre en abanico a través de una serie de sustantivos y frases verbales por diferentes relaciones y oposiciones, como las siguientes:

Hay pueblos

Hay puentes<smiles>[CH]1C[CH]C1</smiles>

Hay que vivir

Hay que morir

Como fondo de toda esa enunciación linguística se percibe el tema de la sociedad en que vivimos.

Una novedad que encontramos es la experiencia teatral de J. Llinás, "Lorsque the monster called amore...", pieza teatral en un acto, escrita en un collage de jdiomas, en la cual el autor es un personaje con su propio rol. Aparece traducida por Molina.

Y la última innovación incluida es un ensayo de vocabulario surrealista, "Ensayo de rectificaciones del lenguaje", realizado por Molina y Llinás. Comprende una selección de veinte palabras, cuyas definiciones o significados responden a múltiples y desconcertantes relaciones entre la palabra y la realidad, un ejemplo es el siguiente:

ARTE: (lat. ars) Sustancia grasa obtenida de la parafina y aceite denso de petróleo. Usase en farmacia y perfumería.

En el intervalo entre el segundo y el tercer número de A PARTIR DE CERO, apareció otra revista, LETRA $Y$ LINEA, que sin tener una orientación surrealista definida contribuyó a la difusión del movimiento. La dirigía Pellegrini 
y actuaban como secretarios Osvaldo Svanascini y Mario Trejo y el comité de redacción estaba integrado por Miguel Brascó, C. Latorre, J. Llinás, E. Molina, Alberto Vanasco y Ernesto E. Rodríguez. Reunía a surrealistas declarados y a otros que no lo eran.

Su existencia fue más prolífera, alcanzó a editar cuatro números, el primero en octubre de 1953, y los siguientes en noviembre, diciembre-enero $1954 \mathrm{y}$ el último en julio de ese año. Constaba de dieciséis páginas tipo tabloide (40 $\mathrm{cm}$. X $29 \mathrm{~cm}$.), ilustrada con reproducciones de obras de artes y fotografías de escritores y poetas mencionados.

Tenía como objetivos estar al servicio de la cultura, responder a sus necesidades y ser campo de experimentación y ensayo de las fuerzas creadoras de los nuevos escritores e invitaba a colaborar a todos aquellos que tuvieran algo que decir, criticar o polemizar. $Y$ continuó con la difusión de la obra de poetas surrealistas como Aimé Cesaire, W. Lam, F. Picabia e incluyó también poetas argentinos.

El tercer número fue el más polémico de todos, fue criticado por Borges y Biov Casares en la revista BUENOS AIRES LITERARIA4, i a causa de la nota crítica de C. Latorre, "Sur y la cultura italiana", se originó la polémica entre Osiris Troiani y A. Pelleprini y también intervino Miguel Brascó.

Durante este período la labor del grupo fue activa y productiva, publicaron dos revistas, defendieron sus principios

4 En "De aporte positivo", cuento-crítica firmado por $H$. Bustos DOMEQ. que apareció en BUENOS AIRES LITERARIA $N^{\circ} 17$ (febrero de 1954), pp.61-64. LOS surrealistas respondieron en LETRA Y IINEA 4 ijulio de 19541 , p. 16.

5 Osiris TROIANI inició la polémica con "Epístola a los surrealistas", en CAPRICORNIO $\mathrm{N}^{\circ} 5$ (marzoabril de 1954), pp. 18 - 23 . Fue contestada por Pellegrini con "Respuesta a Osiris TROIANI", en CAPRICORNIO $\mathrm{N}^{\circ} 7$ (septiembre-octubre de 1954), pp, 9- 15, a la que se sumó una carta de Miguel BRASCO en "Correspondencia", pp. 55, de la misma revista. Troiani dio por fínalizada la discusión con "Fin de un diálogo de sordos", en CONTORNO $\mathrm{N}^{\circ} 5 / 6$ (septiembre de 1955), pp. 55-57. 
e irradiaron su influencia hacia otros poetas que sin mostrar adhesión al movimiento denotan en su obra su huella.

\section{Evolución y tronsformación (1958-1973).}

Esta última etapa se inicia con $B O A$, revista trimestral, dirigida por J. Llinás, quien había vivido en París y se había relacionado con el grupo "Phases". Estaba impresa con esmero y buen material y en sus páginas reunía expresiones poéticas y pictóricas. Estas últimas reproducidas en color y blanco y negro. Tenía corresponsales en Alemania, Bélgica, Canadá, Dinamarca, Egipto, Francia, Italia, México, Polonia, Portugal y Suecia. Alcanzó a publicar tres números, el primero en mayo de 1958; el segundo en junio del mismo año con motivo de la presentación en Buenos Aires de la exposición "Phases"; $y$ el tercero, en julio de 1960.

De ellos interesan los editoriales: "La Bolsa y la Vida", del primero, "El cero es rey", del segundo y "La gran mentira" del tercero: todos firmados por Llinás. En ellos se manifiesta la continuación del pensamiento surrealista, referido a un ámbito más amplio que el país, se busca la universalidad y se clama por la transformación del arte. También se incluye la poesía de la segunda generación surrealista europea a través de colaboraciones de Jean Pierre Duprev, Julien Torma, Edouard Jaguer, etc. Y colaboran los poetas argentinos: Antonio Porchia, Rodolfo Alonso, Mario Trejo, Francisco Urondo, Luis Mesa, Raúl Gustavo Aguirre, Edgar Bayley y Alberto Vanasco.

Esta revista fue una experiencia completamente diferente de las anteriores, aparece como el esfuerzo de una sola persona visible, amplía el horizonte de acción hacia nuevos derroteros para el arte y coordina la divulgación de la nueva pintura y poesía, presenta nuevos modelos e incita a aventurarse por nuevas sendas a partir de las ya abiertas por el movimiento.

La última revista que reunió al grupo fue LA RUEDA, dirigida por Jorge Souza. Integraban su comité de redacción: C. Latorre, J. Llinás, F. Madariaga, E. Molina y A. Pellegrini, 
además de Edgar Bayley. Editó sólo un número en julio-agosto de 1967. Continuaba la labor iniciada por $B O A$ y se presentaba abierta a todas las corrientes de vanguardia. Entre sus colaboradores extranjeros figuraban Octavio Paz, Robert Benayaum, Jean Jacques Lebel y André Bretón.

BOA y LA RUEDA muestran la evolución que se había ido operando en la proyección del surrealismo como modalidad argentina, se amplía el horizonte poético y surge un deseo de universalidad. La poesía pasa a ser vida y también lenguaje y se buscan nuevas formas para su expresión.

Advertimos que en todas las manifestaciones que hemos considerado, la personalidad de Pellegrini fue la figura rectora y aglutinante del grupo. Sea cual fuere su función en la experiencia literaria, su pensamiento trasciende $v$ gravita en aquellas. Por eso hemos elegido la fecha de su muerte, el año 1973, para cerrar esta fase y la travectoria del grupo.

Podríamos decir, usando el lenguaje de Pellegrini, que estas manifestaciones son "una multitud de llamas. surgidas del mismo fuego, que dan iuz propia, pero que a cierta distancia parecen una sola hoguera".

Universidad Nacional de San Juan 